\title{
CD146 Promoter Polymorphism (rs3923594) Is Associated with Recurrence of Clear Cell Renal Cell Carcinoma in Chinese Population
}

\author{
Gang Feng, ${ }^{1}$ Hou-Bao Huang, ${ }^{2}$ Xiao-Bing Ye, ${ }^{3}$ Peng Zhang, ${ }^{1}$ Jian-Jun Huang, \\ Li-Zhu Huang, ${ }^{1}$ Long Cheng, ${ }^{1}$ Chun Pu, ${ }^{1}$ and Guorong $\mathrm{Li}^{4}$ \\ ${ }^{1}$ Clinical Laboratory, The First Affiliated Hospital of Wannan Medical College, Wuhu, Anhui 241001, China \\ ${ }^{2}$ Department of Urology, The First Affiliated Hospital of Wannan Medical College, Wuhu, Anhui 241001, China \\ ${ }^{3}$ Department of Oncology, The First Affiliated Hospital of Wannan Medical College, Wuhu, Anhui 241001, China \\ ${ }^{4}$ Department of Urology, North Hospital, CHU of Saint-Etienne, 42055 Saint-Etienne, France
}

Correspondence should be addressed to Chun Pu; prchunpu@163.com

Received 14 January 2017; Revised 27 March 2017; Accepted 23 April 2017; Published 24 May 2017

Academic Editor: Tilman Todenhöfer

Copyright (c) 2017 Gang Feng et al. This is an open access article distributed under the Creative Commons Attribution License, which permits unrestricted use, distribution, and reproduction in any medium, provided the original work is properly cited.

\begin{abstract}
Introduction. CD146 is a membrane signal receptor in tumor-induced angiogenesis. However, limited studies have focused on the CD146 promoter polymorphisms in clear cell renal cell carcinoma (ccRCC). Purpose. The purpose of this study was to investigate the association between polymorphisms located in the promoter region of the CD146 gene and characteristics of ccRCC in Chinese population. The association between the CD146 promoter polymorphisms and CD146 expression was also investigated in ccRCC. Materials and Methods. A total of 600 samples including 300 ccRCC patients and 300 healthy controls were collected for analysis of the CD146 promoter polymorphisms by direct sequence. The CD146 expressions were measured by qRT-PCR. Results. We had not found any significant differences in genotypic and allelic frequencies of CD146 promoter polymorphisms between ccRCC patients and controls. The rs3923594 was associated with stage and metastasis (300 cases) and recurrence (263 cases) of ccRCC in Chinese population. A significant association was also observed between the rs3923594 and CD146 expression (227 cases) in ccRCC. Conclusions. CD146 promoter polymorphisms were not associated with the risk of ccRCC in Chinese population. The rs3923594 was an independent predictor of recurrence in Chinese patients with localized ccRCC.
\end{abstract}

\section{Introduction}

Renal cell carcinoma (RCC) is a common solid renal malignancy in adults worldwide [1]. In China, the incidence of RCC ranks second among malignant tumors of the urinary system, with an average increase rate at $7.6 \%$ per year [2]. The clear cell RCC (ccRCC) accounts for $70 \%$ to $85 \%$ of all kidney cancers and is the most aggressive subtype with the highest rate of metastasis and mortality [3].

Most of the patients with ccRCC have presented with a localized disease at the time of diagnosis. The goal of surgery is to cure these patients. Unfortunately, up to $40 \%$ of all patients will present with recurrent disease after surgery. The recurrence of ccRCC usually occurs within 3 years after surgery [4]. Thus, there is a need to screen patients who are at risk of recurrence after surgery.

CD146, also known as MCAM or MUC18, is a membrane calcium-independent glycoprotein adhesion molecule, which was identified as a tumor angiogenesis marker [5]. Previous studies had confirmed that CD146 presented in most blood vessels and might involve metastasis via the vascular system in cervical and endometrial cancer $[6,7]$. Our previous study had also reported that CD146 was overexpressed in ccRCC and associated with metastasis or recurrence of ccRCC [8].

Many studies have explored that polymorphisms located in the promoter region of a gene could alter gene expression by affecting the transcriptional rate [9]. Thus, we speculate 
TABLE 1: The sequences of primers, position of amplification, and length of product.

\begin{tabular}{|c|c|c|c|c|c|}
\hline & & Sequence $\left(5^{\prime} \rightarrow 3^{\prime}\right)$ & Start & Stop & Fragment \\
\hline \multirow{2}{*}{ Primer 1} & Forward & CCCGAGACACCTGTCACTAC & \multirow{2}{*}{+17} & \multirow{2}{*}{-242} & \multirow{2}{*}{$259 \mathrm{bp}$} \\
\hline & Reverse & GAGGGCGAGAGCCAAGTGAG & & & \\
\hline \multirow{2}{*}{ Primer 2} & Forward & TGGTGCAATCGTTCTGGGAA & \multirow{2}{*}{-216} & \multirow{2}{*}{-494} & \multirow{2}{*}{$269 \mathrm{bp}$} \\
\hline & Reverse & GGTAGTGACAGGTGTCTCGG & & & \\
\hline \multirow{2}{*}{ Primer 3} & Forward & GTTTGAAGGGACAGCCCAGA & \multirow{2}{*}{-469} & \multirow{2}{*}{-628} & \multirow{2}{*}{$160 \mathrm{bp}$} \\
\hline & Reverse & GCTTCCCAGAACGATTGCAC & & & \\
\hline \multirow{2}{*}{ Primer 4} & Forward & ACTGAGTTCCAGGGTAGGCT & \multirow{2}{*}{-613} & \multirow{2}{*}{-775} & \multirow{2}{*}{162 bp } \\
\hline & Reverse & GCTGTCCCTTCAAACGCAAG & & & \\
\hline
\end{tabular}

Transcription start site is defined as +1 .

that the polymorphisms located in the promoter region of the CD146 gene might be associated with the abnormal CD146 gene expression. The present study aimed to investigate the association between polymorphisms located in the promoter region of the CD146 gene and characteristics of ccRCC in Chinese population. The association between the CD146 promoter polymorphisms and CD146 gene expression was also investigated in ccRCC.

\section{Materials and Methods}

2.1. Patients and Healthy Controls. Peripheral blood samples were obtained from 300 sporadic ccRCC patients and 300 controls between February 2012 and May 2016. All the patients had histopathologically confirmed incident ccRCC and had undergone radical or partial nephrectomy. Tumor stage was assigned according to the 2010 American Joint Committee on Cancer (AJCC) TNM (tumor-node-metastasis) classification. Tumor nuclear grading was based on the criteria of Fuhrman by a single pathologist. Patients with an $\mathrm{M}$ classification of 0 or an $\mathrm{N}$ classification of 0 were considered to have localized disease (M0N0). The presence or absence of necrosis and the extent of necrosis were evaluated for all specimens. Estimation of the percentage of tumor necrosis was based on the imageological description of the tumor. The extent of necrosis was graded according to the following scale: 0 , no necrosis; $1,<25 \%$ necrosis; $2,25-50 \%$ necrosis; 3, 51-75\% necrosis; and 4, 76-100\% necrosis [10].

None of the patients had ever received immunotherapy or targeted therapies before surgery. A total of 300 controls were recruited from healthy volunteers who went for regular physical check-up at our hospital and were frequencymatched to the cases on sex and age. All study subjects were all of ethnic Chinese origin and provided with written consent. The study protocol was approved by the Institutional Ethical Review Board of Wannan Medical College.

2.2. Follow-Up. The follow-up program after operation consisted of a clinical examination, laboratory tests, and a pulmonary X-ray at 3 months, then every 6 months during the first 3 years, and thereafter examination yearly. Abdominal computed tomography was performed at 6 and 24 months after nephrectomy and additional imaging used whenever indicated. All patients had adequate information for followup. The maximum follow-up time was 54 months (last follow-up in August 2016) and the median follow-up time was 24.5 months. The recurrence-free survival (RFS) time was calculated from the date of operation until a patient's known recurrence or until the date of the last follow-up visit.

2.3. DNA Isolation and Genotyping. Total genomic DNA was isolated from venous blood using the QIAamp DNA Mini Kit (Qiagen S.A.) according to the manufacturer's protocol. Four fragments located in the promoter region of the CD146 gene were amplified, respectively. The sequences and positions of primers are shown in Table 1 . The reactions were performed in a total volume of $25 \mu \mathrm{l}$ containing $1 \mu \mathrm{g}$ genomic DNA, $5 \mu \mathrm{M}$ of each primer, and $12.5 \mu \mathrm{l} 2 \times$ PCR Master Mix (Thermo Scientific; Pittsburgh, PA, USA). The cycling parameters for PCR were as follows: denaturation at $94^{\circ} \mathrm{C}$ for $4 \mathrm{~min}$, followed by 35 cycles of denaturation at $94^{\circ} \mathrm{C}$ for $40 \mathrm{~s}$, annealing at $59^{\circ} \mathrm{C}$ for $30 \mathrm{~s}$, and extension at $72^{\circ} \mathrm{C}$ for $60 \mathrm{~s}$. Specificity of PCR product was confirmed by $5 \%$ polyacrylamide gel electrophoresis, and products were sequenced by an ABI3730xl DNA Analyzer.

2.4. CD146 Expression. All tumor samples were obtained immediately after the operation and put into a liquid nitrogen freezer for storage. The total RNA was isolated (RNeasy Mini Kit, Qiagen S.A.) and transcribed to cDNA (High-Capacity RNA-to-cDNA Kit; Life Technologies). Amplification and detection of CD146 mRNA were performed as previously described [8]. CD146 gene expression was defined as a ratio of CD146 mRNA to beta-actin mRNA and then multiplied by 1000 for easier tabulation.

2.5. Statistical Analysis. All allele frequencies of polymorphism were tested against departure from Hardy-Weinberg equilibrium (HWE) before the analysis. The demographic characteristics, selected variables, and frequencies of genotypes in patients and controls were compared by Student's $t$-test for continuous variables and chi-square test or Fisher's exact test for categorical variables. The associations between the polymorphisms and ccRCC risk were estimated by computing the odds ratios (ORs) and 95\% confidence intervals (CIs) from unconditional logistic regression analysis with the adjustment for possible confounders. Univariate or multivariate Cox regression analysis was done to determine predictive factors of recurrence of localized ccRCC by estimating the hazard ratios (HRs) and their 95\% CIs. The recurrence-free 
TABLE 2: Distribution of selected variables between the ccRCC patients and controls.

\begin{tabular}{|c|c|c|c|}
\hline Variables & Patients & Controls & $P$ value \\
\hline Age $($ mean $\pm S D)$, year & $58.2 \pm 11.6$ & $58.0 \pm 11.1$ & 0.994 \\
\hline$\leq 57$ & 136 & 142 & 0.623 \\
\hline$>57$ & 164 & 158 & \\
\hline Sex & & & 0.248 \\
\hline Male & 178 & 164 & \\
\hline Female & 122 & 136 & \\
\hline \multicolumn{4}{|l|}{ Tumor size (diameter) } \\
\hline$\leq 2 \mathrm{~cm}$ & 73 & & \\
\hline$>2 \mathrm{~cm}$ & 227 & & \\
\hline \multicolumn{4}{|l|}{ Tumor stage } \\
\hline $\mathrm{T} 1+\mathrm{T} 2$ & 259 & & \\
\hline $\mathrm{T} 3+\mathrm{T} 4$ & 41 & & \\
\hline \multicolumn{4}{|l|}{ Tumor grade } \\
\hline $1+2$ & 283 & & \\
\hline $3+4$ & 17 & & \\
\hline \multicolumn{4}{|l|}{ Extent of necrosis } \\
\hline 0 & 186 & & \\
\hline 1 & 67 & & \\
\hline 2 & 28 & & \\
\hline 3 & 15 & & \\
\hline 4 & 4 & & \\
\hline \multicolumn{4}{|l|}{ Lymph node metastasis } \\
\hline Negative & 271 & & \\
\hline Positive & 29 & & \\
\hline \multicolumn{4}{|l|}{ Distant metastasis } \\
\hline Negative & 270 & & \\
\hline Positive & 30 & & \\
\hline \multicolumn{4}{|l|}{ Recurrence } \\
\hline Negative & 242 & & \\
\hline Positive & 21 & & \\
\hline
\end{tabular}

survival curves were calculated by the Kaplan-Meier method and compared by the log-rank test. All statistical analyses were performed using SPSS 13.0 software (SPSS Inc.). $P<0.05$ in a two-side test was considered statistically significant.

\section{Results}

3.1. Characteristics of Patients with ccRCC and Controls. The distributions of selected characteristics of the $300 \mathrm{ccRCC}$ patients and 300 controls are shown in Table 2. There were no significant differences between patients and controls according to age $(P=0.994)$ and sex $(P=0.248)$.

3.2. Genotype Distribution of CD146 Promoter Polymorphisms in ccRCC Patients and Controls. We had detected six single nucleotide polymorphisms (SNPs) of CD146 promoter (Table 3). The genotype frequencies of all SNPs were conformed to Hardy-Weinberg equilibrium (all $P>0.05$ ). No significant differences in genotype and allele frequencies were observed between patients with ccRCC and controls (Table 3).
TABLE 3: Genotype and allele frequencies of CD146 promoter polymorphisms among the ccRCC patients and controls.

\begin{tabular}{|c|c|c|c|c|}
\hline Genotype & Patients & Controls & $P^{\mathrm{a}}$ value & $\mathrm{OR}^{\mathrm{a}}(95 \% \mathrm{CI})$ \\
\hline \multicolumn{5}{|l|}{ rs3923594 } \\
\hline GG & 194 & 216 & 0.095 & 1.000 (reference) \\
\hline GT & 95 & 75 & 0.064 & $0.677(0.571-0.992)$ \\
\hline TT & 11 & 9 & 0.463 & $0.713(0.289-1.760)$ \\
\hline G allele & 483 & 507 & 0.068 & \\
\hline $\mathrm{T}$ allele & 117 & 93 & & \\
\hline \multicolumn{5}{|c|}{ rs543070476 } \\
\hline GG & 236 & 249 & 0.393 & 1.000 (reference) \\
\hline GA & 55 & 44 & 0.206 & $0.753(0.485-1.169)$ \\
\hline AA & 9 & 7 & 0.548 & $0.735(0.268-2.011)$ \\
\hline G allele & 527 & 542 & 0.165 & \\
\hline A allele & 73 & 58 & & \\
\hline \multicolumn{5}{|l|}{ New 1} \\
\hline $\mathrm{CC}$ & 256 & 269 & 0.474 & 1.000 (reference) \\
\hline CG & 44 & 31 & 0.108 & $0.633(0.439-1.119)$ \\
\hline GG & 0 & 0 & & \\
\hline $\mathrm{C}$ allele & 556 & 569 & 0.125 & \\
\hline $\mathrm{G}$ allele & 44 & 31 & & \\
\hline \multicolumn{5}{|l|}{ New 2} \\
\hline AA & 246 & 251 & 0.442 & 1.000 (reference) \\
\hline $\mathrm{AC}$ & 54 & 49 & 0.220 & $0.703(0.336-1.155)$ \\
\hline $\mathrm{CC}$ & 0 & 0 & & \\
\hline A allele & 546 & 551 & 0.606 & \\
\hline $\mathrm{C}$ allele & 54 & 49 & & \\
\hline \multicolumn{5}{|l|}{ New 3} \\
\hline $\mathrm{CC}$ & 229 & 238 & 0.647 & 1.000 (reference) \\
\hline CA & 71 & 62 & 0.851 & $0.945(0.640-1.285)$ \\
\hline AA & 0 & 0 & & \\
\hline $\mathrm{C}$ allele & 529 & 538 & 0.408 & \\
\hline A allele & 71 & 62 & & \\
\hline \multicolumn{5}{|l|}{ New 4} \\
\hline $\mathrm{TT}$ & 244 & 259 & 0.403 & 1.000 (reference) \\
\hline TG & 53 & 40 & 0.131 & $0.769(0.517-1.098)$ \\
\hline GG & 3 & 1 & 0.060 & $0.698(0.554-0.991)$ \\
\hline $\mathrm{T}$ allele & 541 & 558 & 0.077 & \\
\hline G allele & 59 & 42 & & \\
\hline
\end{tabular}

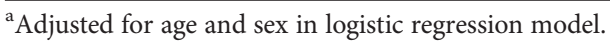

3.3. Associations between CD146 Promoter Polymorphisms and Clinicopathological Characteristics of ccRCC. There were not any significant associations between five SNPs and clinicopathological characteristics of ccRCC in this study. Significant associations were found between rs3923594 and stage $(P=0.030)$, metastasis in lymph node $(P=0.007)$, and distant metastasis $(P=0.005)$ (Table 4$)$.

3.4. Associations between CD146 Promoter Polymorphisms and Recurrence of Localized ccRCC. None of significant associations were found between five SNPs and recurrence of localized ccRCC. As shown in Table 5, the rs3923594 was 
TABLE 4: Associations of the rs3923594 with clinicopathologic variables of ccRCC.

\begin{tabular}{|c|c|c|c|}
\hline & \multicolumn{3}{|c|}{ Genotype } \\
\hline & GG & GT & TT \\
\hline \multicolumn{4}{|l|}{ Stage } \\
\hline $\mathrm{T} 1+\mathrm{T} 2$ & 172 & 80 & 7 \\
\hline $\mathrm{T} 3+\mathrm{T} 4$ & 22 & 15 & 4 \\
\hline $\mathrm{OR}^{\mathrm{a}}(95 \% \mathrm{CI})$ & 1.000 (reference) & $1.505(0.732-3.093)$ & $4.287(1.152-15.952)$ \\
\hline$P$ value & & 0.266 & 0.030 \\
\hline \multicolumn{4}{|l|}{ Grade } \\
\hline $1+2$ & 183 & 91 & 9 \\
\hline $3+4$ & 11 & 4 & 2 \\
\hline $\mathrm{OR}^{\mathrm{a}}(95 \% \mathrm{CI})$ & 1.000 (reference) & $0.735(0.218-2.472)$ & $\begin{array}{c}3.150 \\
(0.570-17.406)\end{array}$ \\
\hline$P$ value & & 0.618 & 0.188 \\
\hline \multicolumn{4}{|c|}{ Metastasis in lymph node } \\
\hline Negative & 179 & 85 & 7 \\
\hline Positive & 15 & 10 & 4 \\
\hline $\mathrm{OR}^{\mathrm{a}}(95 \% \mathrm{CI})$ & 1.000 (reference) & $1.497(0.639-3.508)$ & $6.414(1.668-24.661)$ \\
\hline$P$ value & & 0.353 & 0.007 \\
\hline \multicolumn{4}{|l|}{ Distant metastasis } \\
\hline Negative & 184 & 80 & 6 \\
\hline Positive & 10 & 15 & 5 \\
\hline $\mathrm{OR}^{\mathrm{a}}(95 \% \mathrm{CI})$ & 1.000 (reference) & $1.761(0.828-4.125)$ & $6.982(1.788-29.654)$ \\
\hline$P$ value & & 0.114 & 0.005 \\
\hline
\end{tabular}

${ }^{a}$ Adjusted for age and sex in logistic regression model.

TABLE 5: Univariate and multivariate Cox regression analysis in patients with localized ccRCC.

\begin{tabular}{|c|c|c|c|c|c|c|}
\hline \multirow{3}{*}{ Variables } & \multicolumn{6}{|c|}{ RFS } \\
\hline & & Univariate & & & Multivariate & \\
\hline & HR & $95 \% \mathrm{CI}$ & $P$ value & $\mathrm{HR}$ & $95 \% \mathrm{CI}$ & $P$ value \\
\hline Age $(\leq 57$ versus $>57)$ & 1.290 & $0.601-3.684$ & 0.372 & & & \\
\hline Sex (male versus female) & 1.481 & $0.714-3.576$ & 0.382 & & & \\
\hline Tumor size ( $\leq 2$ versus $>2 \mathrm{~cm}$ ) & 2.109 & $1.240-4.843$ & 0.006 & 1.853 & $1.008-3.451$ & 0.023 \\
\hline Stage $(\mathrm{T} 1+\mathrm{T} 2$ versus $\mathrm{T} 3+\mathrm{T} 4)$ & 4.828 & $2.754-8.266$ & $<0.001$ & 2.963 & $1.438-5.157$ & 0.005 \\
\hline Grade $(1+2$ versus $3+4)$ & 3.996 & $2.212-7.249$ & $<0.001$ & 2.852 & $1.339-5.274$ & 0.003 \\
\hline Presence of necrosis (yes versus no) & 2.548 & $1.339-5.982$ & 0.012 & 1.985 & $1.021-3.682$ & 0.019 \\
\hline rs3923594 (GG versus GT + TT) & 2.788 & $1.186-6.586$ & 0.021 & 2.116 & $1.053-4.107$ & 0.034 \\
\hline
\end{tabular}

significantly associated with recurrence of localized ccRCC (HR, 2.788; 95\% CI, 1.186-6.586; $P=0.021$ ) by the univariate analysis. A multivariate Cox proportional hazard model indicated that tumor size, stage, grade, presence of necrosis, and rs3923594 (all $P<0.05$ ) were independent predictors of recurrence of localized ccRCC. Kaplan-Meier analyses were applied to compare RFS in patients with different genotypes of rs3923594 (TT or GT + TT, GG). The patients (M0N0) with the TT or GT + TT genotype demonstrated a significantly lower RFS $(P=0.023)$ compared with those with the GG genotype (Figure 1).

3.5. Associations between CD146 Promoter Polymorphisms and CD146 Gene Expression at mRNA Level. None of significant associations were found between five SNPs with CD146 gene expression, whereas rs3923594 was associated with CD146 gene expression at mRNA level in 227 specimens. The mean of CD146 gene expression in patients with genotype TT of rs3923594 (4.84 \pm 1.22$)$ was significantly higher than that in those with genotype GG (3.96 \pm 0.85 , $P=0.014)$. The mean of CD146 gene expression in patients with genotype GT of rs3923594 (4.26 \pm 1.14$)$ was also higher than that in those with genotype GG, but the difference did not reach statistical significance $(P=0.119)$ (Figure 2$)$.

\section{Discussion}

Continuous and frequent radiological examinations, such as CT, MRI, or bone scintigraphy, have served an important role in monitoring recurrence of localized ccRCC during 


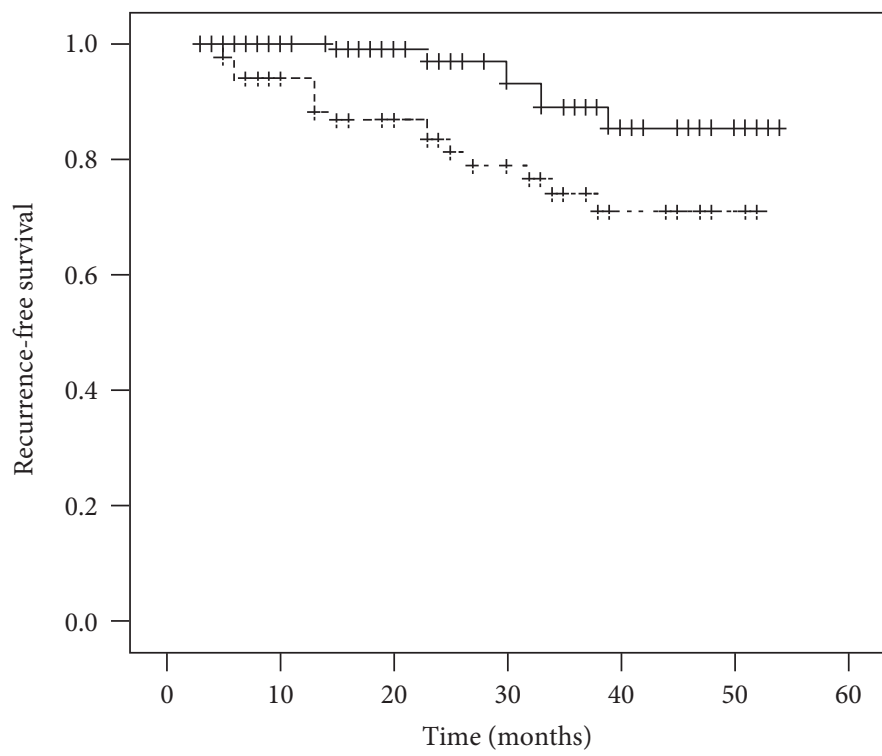

\begin{tabular}{ll} 
rs3923594 \\
$\square$ GG \\
\hdashline$\quad$ TT or TT + GT \\
$+-\quad 1$-censored \\
$-1 \quad 2$-censored
\end{tabular}

FIGURE 1: Kaplan-Meier survival curves illustrate recurrence-free survival according to the genotype of rs3923594. Patients with the TT or GT + TT had a significantly higher recurrence rate than those with the GG $(P=0.023)$.

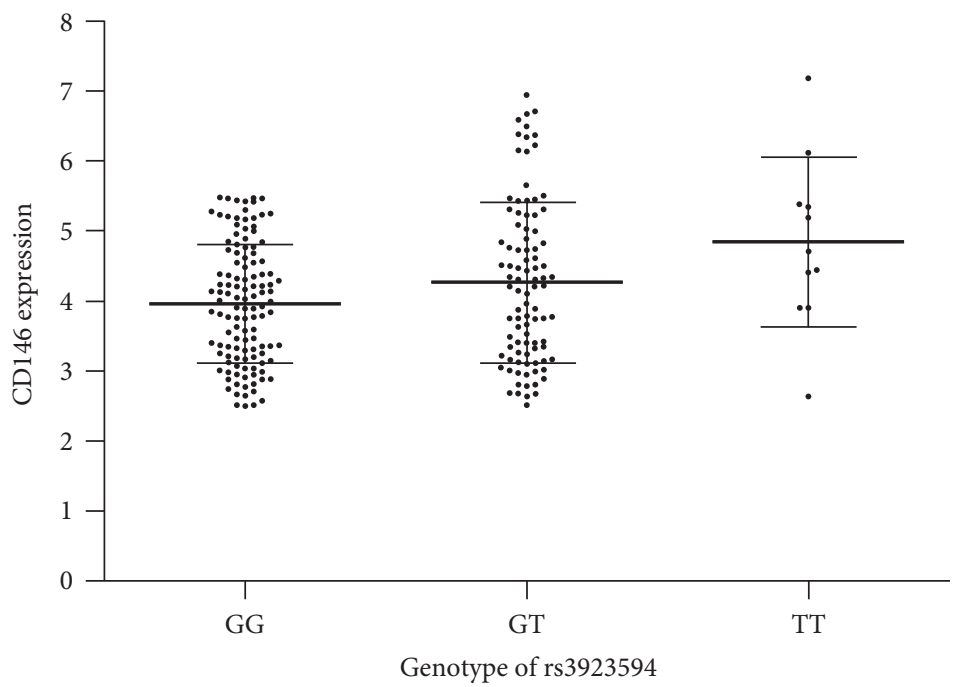

FIGURE 2: CD146 expression at mRNA levels in groups with different rs3923594 genotypes.

follow-up [11]. Compared with those of more expensive imaging methods, analyses of tumor biomarkers have no risk of radiation exposure and are easily available and cost-effective.

Currently, many studies have reported that polymorphism of NFKB1 [12], PTPRD [13], CASP8 [14], GSTM3 [15], and BTLA [16] is related to the risk of RCC. Some researchers have further presented the associations between survival of RCC and polymorphism of IL-4 [17], VEGF [18], CYP3A5, and ABCB1 [19].
In this study, we had detected six SNPs located in the promoter region of the CD146 gene. Firstly, we had investigated the associations between SNPs and the risk of ccRCC in Chinese population. The genotype distributions of all SNPs were in HW in the control group, which indicated no population stratification. Between ccRCC patients and controls, we had not found any significant differences in the distribution of genotypes of all SNPs. Therefore, there was no evidence of the association between these CD146 promoter SNPs and the risk of ccRCC in Chinese population. 
We had investigated the associations between CD146 promoter polymorphisms and clinicopathological characteristics of ccRCC in Chinese population. However, the rs543070476, new 1 , new 2 , new 3 , and new 4 were not associated with clinicopathological characteristics of ccRCC. The significant associations were found between rs3923594 and stage, lymph node metastasis, and distant metastasis. These results suggested that the rs3923594 was associated with tumor stage and metastasis of ccRCC in Chinese population. None of significant association was found between the rs3923594 and grade in this study. Although only 17 patients have grade 3 or 4 in our study, this result needs further validation.

We also investigated the associations between rs3923594 and recurrence of localized ccRCC in Chinese population. Univariate analysis demonstrated that the rs3923594 was significantly associated with recurrence of localized ccRCC. Furthermore, multivariate analysis reconfirmed the independence of rs3923594 in predicting recurrence, just like tumor size, stage, grade, and presence of necrosis. Thus, rs3923594 may serve as a valuable predictor of recurrence in patients with localized ccRCC.

We had found the association between the rs3923594 and CD146 gene expression at mRNA level in patients with ccRCC. However, the specimens of small tumors (diameter $\leq 2 \mathrm{~cm}, 73$ cases) had not been collected in this study, which might reduce the reliability of this result. We had also found that the mean of CD146 gene expression at mRNA level in patients with genotype GG of rs3923594 was lowest. However, the higher CD146 gene expressions were also found in small number of these patients. We consider that the promoter polymorphism may be just one of the factors that affect CD146 gene expression. The exact mechanism remains to be elucidated in the future.

When interpreting our results, some limitations need to be considered. Firstly, some risk factors of ccRCC, such as hypertension, obesity, and smoking, were not collected in our analyses. Secondly, because of the small sample size and the short follow-up, statistical significance should be interpreted with caution. Thirdly, CD146 gene expression had been measured in only partial patients. Further validation in a larger population and functional characterizations are needed in our future studies.

\section{Conclusion}

In summary, CD146 promoter polymorphisms were not associated with the risk of ccRCC in Chinese population. The rs3923594 was an independent predictor of recurrence in Chinese patients with localized ccRCC.

\section{Conflicts of Interest}

The authors declare that there is no conflict of interests regarding the publication of this paper.

\section{Acknowledgments}

This research was supported by the Anhui Natural Science Foundation (1508085MH157).

\section{References}

[1] R. L. Siegel, K. D. Miller, and A. Jemal, "Cancer statistics, 2015," CA: A Cancer Journal for Clinicians, vol. 65, no. 1, pp. 5-29, 2015.

[2] T. Bai, L. Wang, D. Wang et al., "Clinicopathologica epidemiological characteristics and change tendencies of renal cell carcinoma in Shanxi Province of China from 2005 to 2014," PLos One, vol. 10, no. 12, article e0144246, 2015.

[3] G. Feng, F. Jiang, C. Pan, C. Pu, H. Huang, and G. Li, "Quantification of peripheral blood CD133 mRNA in identifying metastasis and in predicting recurrence of patients with clear cell renal cell carcinoma," Urologic Oncology, vol. 32, no. 1, p. 44.e9-14, 2014.

[4] G. Li, G. Feng, A. Gentil-Perret, C. Genin, and J. Tostain, "Serum carbonic anhydrase 9 level is associated with postoperative recurrence of conventional renal cell cancer," The Journal of Urology, vol. 180, no. 2, pp. 510-513, 2008, discussion 513-4.

[5] T. Tu, C. Zhang, H. Yan et al., "CD146 acts as a novel receptor for netrin-1 in promoting angiogenesis and vascular development," Cell Research, vol. 25, no. 3, pp. 275-287, 2015.

[6] H. Zhang, J. Zhang, Z. Wang et al., "CD146 is a potential marker for the diagnosis of malignancy in cervical and endometrial cancer," Oncology Letters, vol. 5, no. 4, pp. 11891194, 2013.

[7] T. Jiang, J. Zhuang, H. Duan et al., "CD146 is a coreceptor for VEGFR-2 in tumor angiogenesis," Blood, vol. 120, no. 11, pp. 2330-2339, 2012.

[8] G. Feng, F. Fang, C. Liu, F. Zhang, H. Huang, and C. Pu, "CD146 gene expression in clear cell renal cell carcinoma: a potential marker for prediction of early recurrence after nephrectomy," International Urology and Nephrology, vol. 44, no. 6, pp. 1663-1669, 2012.

[9] S. N. Klimosch, A. Försti, J. Eckert et al., "Functional TLR5 genetic variants affect human colorectal cancer survival," Cancer Research, vol. 73, no. 24, pp. 7232-7242, 2013.

[10] J. S. Lam, O. Shvarts, J. W. Said et al., "Clinicopathologic and molecular correlations of necrosis in the primary tumor of patients with renal cell carcinoma," Cancer, vol. 103, no. 12, pp. 2517-2525, 2005.

[11] Y. Wu, Y. S. Kwon, M. Labib, D. J. Foran, and E. A. Singer, "Magnetic resonance imaging as a biomarker for renal cell carcinoma," Disease Markers, vol. 2015, no. 3, Article ID 648495, 9 pages, 2015.

[12] H. Cai, L. Sun, L. Cui et al., "A functional insertion/deletion polymorphism (-94 ins/del ATTG) in the promoter region of the NFKB1 gene is related to the risk of renal cell carcinoma," Urologia Internationalis, vol. 91, no. 2, pp. 206-212, 2013.

[13] Y. Du, T. Su, X. Tan et al., "Polymorphism in protein tyrosine phosphatase receptor delta is associated with the risk of clear cell renal cell carcinoma," Gene, vol. 512, no. 1, pp. 64-69, 2013.

[14] M. de Martino, A. Haitel, G. Schatzl, H. C. Klingler, and T. Klatte, "The CASP8-652 6N insertion/deletion promoter polymorphism is associated with renal cell carcinoma risk and metastasis," The Journal of Urology, vol. 190, no. 2, pp. 717722, 2013.

[15] X. Tan, Y. Wang, Y. Han et al., "Genetic variation in the GSTM3 promoter confer risk and prognosis of renal cell carcinoma by reducing gene expression," British Journal of Cancer, vol. 109, no. 12, pp. 3105-3115, 2013. 
[16] A. Partyka, K. Tupikowski, A. Kolodziej et al., "Association of $3^{\prime}$ nearby gene BTLA polymorphisms with the risk of renal cell carcinoma in the Polish population," Urologic Oncology, vol. 34, no. 9, p. 419.e13-9, 2016.

[17] T. Kleinrath, C. Gassner, P. Lackner, M. Thurnher, and R. Ramoner, "Interleukin-4 promoter polymorphisms: a genetic prognostic factor for survival in metastatic renal cell carcinoma," Journal of Clinical Oncology, vol. 25, no. 7, pp. 845851, 2007.

[18] N. Ma, L. W. Li, and J. L. Cheng, "Predictive value of vascular endothelial growth factor polymorphisms on the clinical outcome of renal cell carcinoma patients," Oncology Letters, vol. 9, no. 2, pp. 651-656, 2015.

[19] M. H. Diekstra, J. J. Swen, E. Boven et al., "CYP3A5 and $\mathrm{ABCB} 1$ polymorphisms as predictors for sunitinib outcome in metastatic renal cell carcinoma," European Urology, vol. 68, no. 4, pp. 621-629, 2015. 


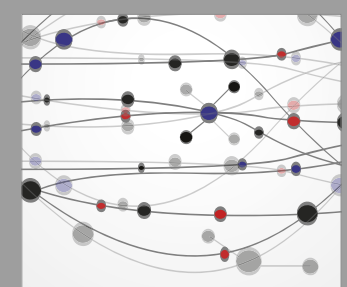

The Scientific World Journal
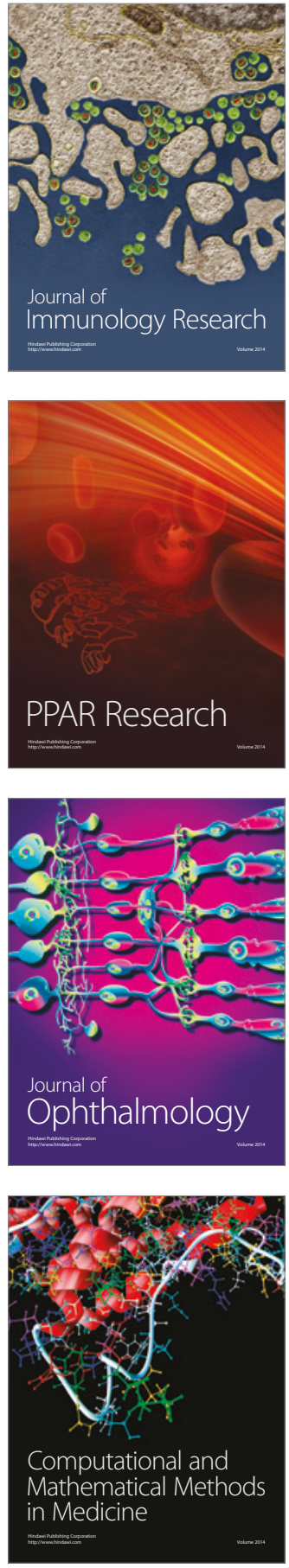

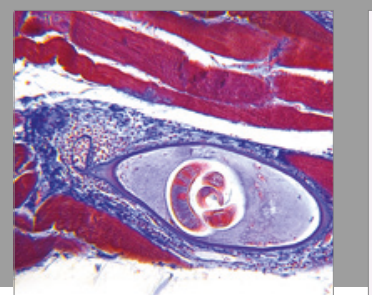

Gastroenterology Research and Practice
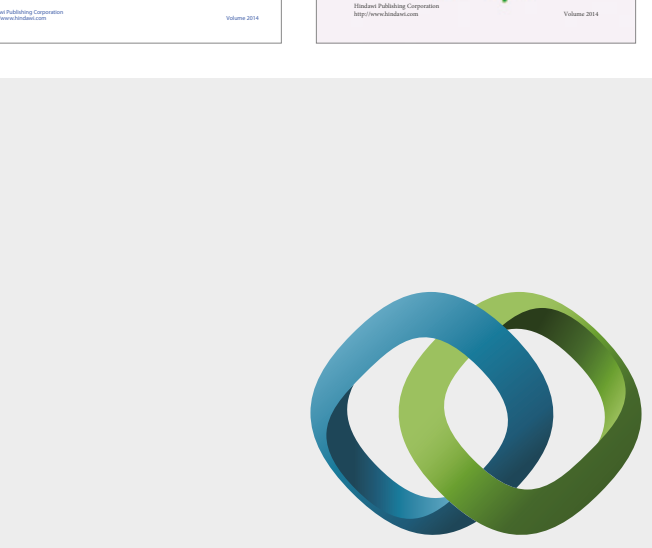

\section{Hindawi}

Submit your manuscripts at

https://www.hindawi.com
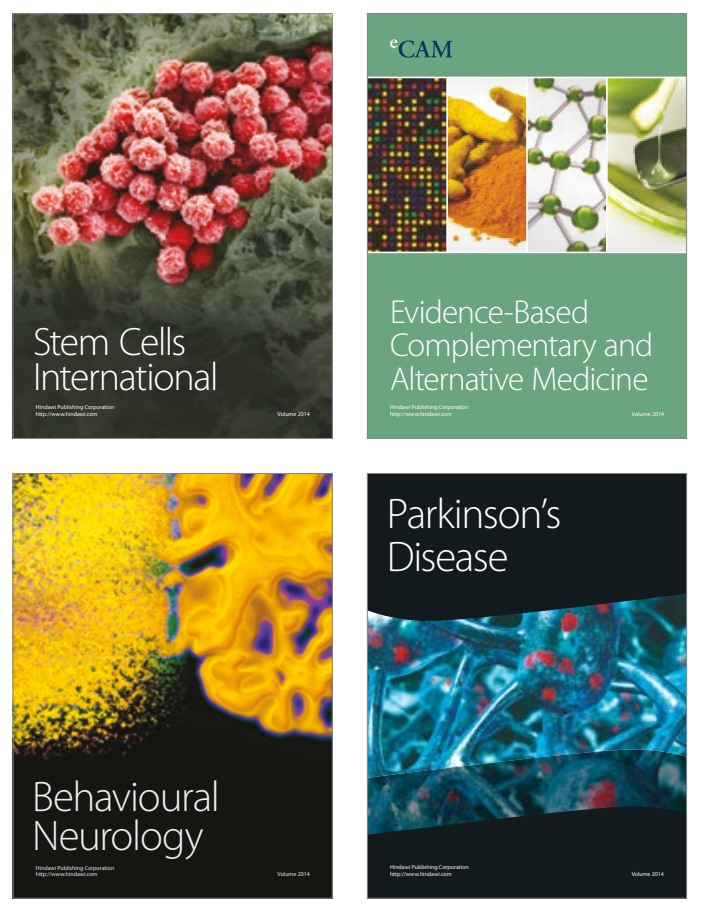
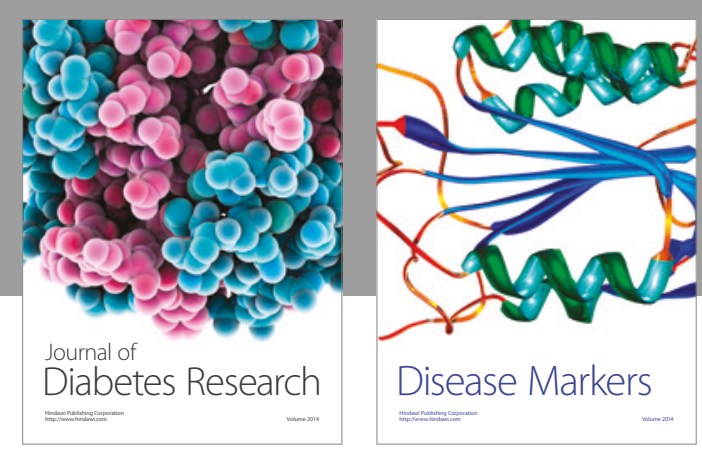

Disease Markers
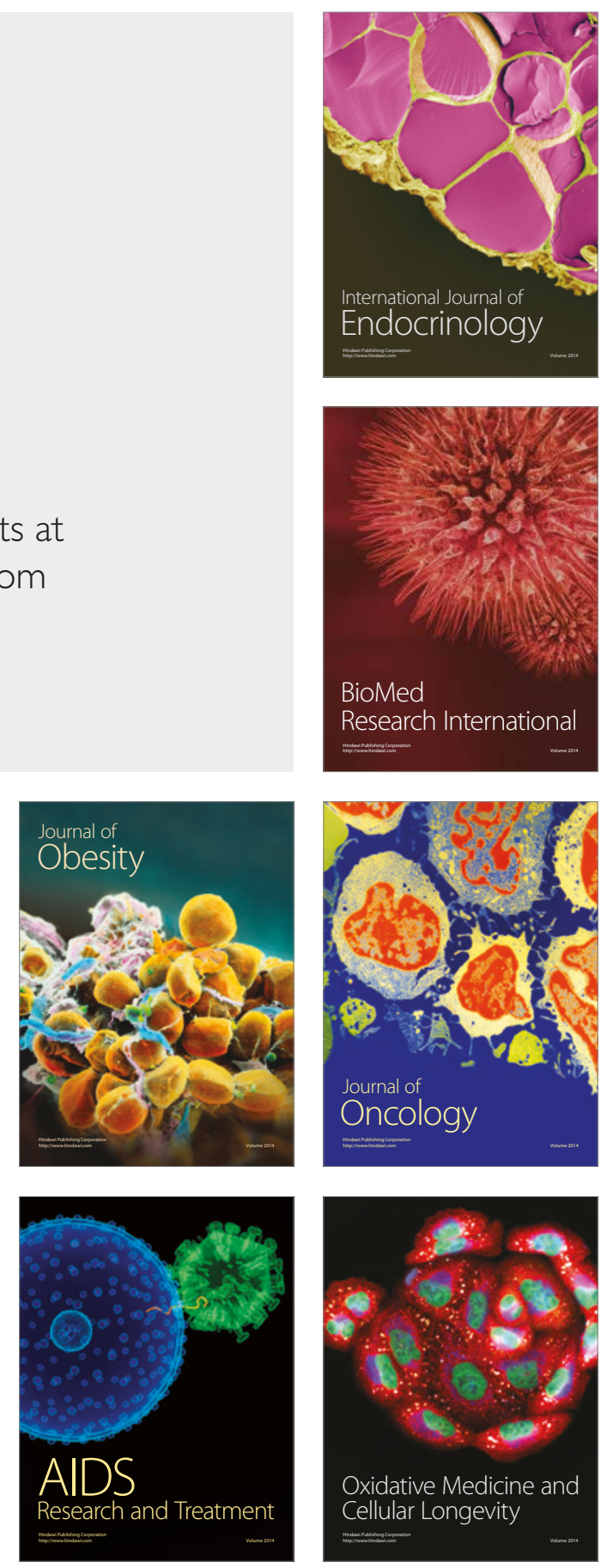